\title{
CONSTRUÇÃO DE MAQUETE PARA DIVULGAÇÃO DA GEODIVERSIDADE DE DUNAS COSTEIRAS
}

\author{
Jéssica Conceição da Silva ${ }^{(a)}$, Beatriz Abreu Machado ${ }^{(b)}$, Thaís Baptista da Rocha ${ }^{(\mathrm{c})}$ \\ (a) Instituto de Geografia, UERJ, silvajessica_19@hotmail.com \\ (b) Instituto de Geografia, UERJ, bia_abreu23@ hotmail.com \\ (c) Departamento de Geografia / Instituto de Geociências, UFF, thaisitc5@yahoo.com.br
}

\section{Eixo: GEODIVERSIDADE, GEOARQUEOLOGIA E PATRIMÔNIO NATURAL}

\begin{abstract}
Resumo
Por mais que sejam importantes e sofram impactos decorrentes da ação humana, a geodiversidade e a geodiversidade costeira não são tão conhecidas quanto à biodiversidade. Por conta disto, a propagação deste tema na sociedade deve ser realizada. Desta problemática surge o Projeto GeoPECS: Geodiversidade costeira no Parque Estadual da Costa do Sol. Com esse projeto, atividades voltadas para a disseminação da geodiversidade costeira, com foco nos vários tipos de dunas costeiras, foram realizadas. Dentre essas atividades, se tem a montagem de maquete, que possibilitou a realização do presente trabalho, cujo objetivo é divulgar a construção de maquete na representação da geodiversidade de dunas costeiras para alunos do ensino fundamental. A utilização da maquete pode ajudar a tornar o ensino deste tema mais estimulante e concreto.
\end{abstract}

Palavras chave: Geodiversidade costeira, dunas costeiras, maquete.

\section{Introdução}

Elementos de geodiversidade estão presentes na vida dos seres humanos nos diversos ambientes por eles visitados ou não. Porém, o que se nota é uma maior visibilidade da biodiversidade. Conforme apontam Brilha (2005) e Araújo e Lopes (2011), a realização de pesquisas, divulgação e conservação da geodiversidade é menor em relação à biodiversidade. O cenário mencionado mostra que é preciso disseminar o conceito de geodiversidade e sua importância na sociedade, mostrando os impactos que estes elementos sofrem e alertando para a necessidade de conservação, através de projetos, por exemplo.

A efetuação de um levantamento bibliográfico expõe a existência de vários conceitos de geodiversidade. De acordo com Rocha et al (2016), aquele proposto pelo Serviço Geológico do Brasil é um dos destaques. Este a conceitua como

"o estudo da natureza abiótica (meio físico) constituída por uma variedade de ambientes, composição, fenômenos e processos geológicos que dão origem às paisagens, rochas, minerais, águas, fósseis, solos, clima e outros depósitos superficiais que propiciam o desenvolvimento da vida na Terra, tendo como 
valores intrínsecos a cultura, o estético, o econômico, o científico, o educativo e o turístico" (CPRM, 2006).

Uma de suas esferas é a geodiversidade costeira, inserida no componente geomorfológico da geodiversidade - um dos quatro componentes propostos por Thomas (2012). De acordo com Baptista et al (2016), no litoral brasileiro é notória a ocorrência de geodiversidade relacionada aos aspectos e às paisagens geomorfológicas. Estas paisagens são bastante variadas por conta de diversas condições climáticas, oceanográficas e de herança geológica (BRANDÃO, 2008). São elementos da geodiversidade costeira as praias e as dunas costeiras, por exemplo.

Considerando a geodiversidade costeira, sua importância, impactos sofridos e a necessidade de aumentar o conhecimento sobre o tema da sociedade, criou-se o Projeto GeoPECS: Geodiversidade costeira no Parque Estadual da Costa do Sol (PECSOL), desenvolvido entre a Universidade do Estado do Rio de Janeiro (UERJ), a Secretaria de Educação do município de Armação de Búzios (RJ) e o Parque Estadual do Costa do Sol. Seu objetivo é tornar público o conceito e os aspectos de geodiversidade costeira em escolas dos municípios que o parque abarca.

O objeto principal do projeto para se trabalhar o tema foram as dunas costeiras. Estas, de acordo com Davidson-Arnott (2010), são feições geomorfológicas que ocorrem em praias arenosas, com um grande aporte sedimentar, que se formam através da chegada destes sedimentos à praia pela ação das ondas e do seu deslocamento através da ação do vento em direção à costa. Segundo Hesp e Walker (2013); Fernandez et al. no prelo, as dunas apresentam as seguintes tipologias: frontal, parabólicas, barcanoides e transgressivas. Inicialmente, a atividade desenvolvida em uma escola local foi a realização de trabalhos de campo. Em seguida, se focou na construção de maquete. Isto deu base para a elaboração do presente trabalho que tem por objetivo divulgar a confecção de maquete na representação da geodiversidade de dunas costeiras voltada para alunos do ensino fundamental.

\section{Materiais e Métodos}

Primeiramente, dois trabalhos de campo foram feitos. Estes tiveram como base a metodologia apresentada por Bento e Araújo (2014) que apresenta as etapas de preparação e execução. A preparação consistiu na escolha da escola, dos pontos de visitação e também de mapas e imagens, ou seja, materiais necessários para se trabalhar o tema. A escola municipal INEFI (Instituto de Educação e Formação Integral Judite Gonçalves), localizada no município de Armação dos Búzios, no estado do Rio de Janeiro, foi escolhida. Esta recebeu o projeto GeoPECS que teve como público os alunos do ensino fundamental inscritos na 
oficina de Educação Ambiental, do professor Marco Antônio da Costa, licenciado em Geografia. Uma apresentação sobre geodiversidade foi feita para alunos e professores.

Os trabalhos de campo, que ocorreram em pontos com várias tipologias de dunas costeiras, aconteceram na etapa de execução, tornando a geodiversidade de dunas costeiras mais palpável para os participantes. Alunos, professores e guardas-parque do Parque Estadual da Costa do Sol participaram destas atividades. Um dos materiais utilizados na confecção de maquete de geodiversidade de dunas costeiras, a areia, foi coletado pelos estudantes.

Além da areia, para a criação da maquete, foi necessário o uso dos seguintes materiais (figura 1): uma régua de 30 centímetros, estilete, caneta esferográfica preta de ponta fina, uma colher, um palito de pirulito, uma placa de isopor medindo 30 x 30 centímetros, cartolina azul (recortada de forma irregular em uma das bordas, no tamanho $30 \times 10$ centímetros), um papel cartão vermelho, três bolas de isopor de 50 milímetros de diâmetro cortadas ao meio, uma cola de isopor, uma cola branca, um pacote de massa de modelar amarela e outro azul e grama de crepom ou papel crepom picado na cor verde.

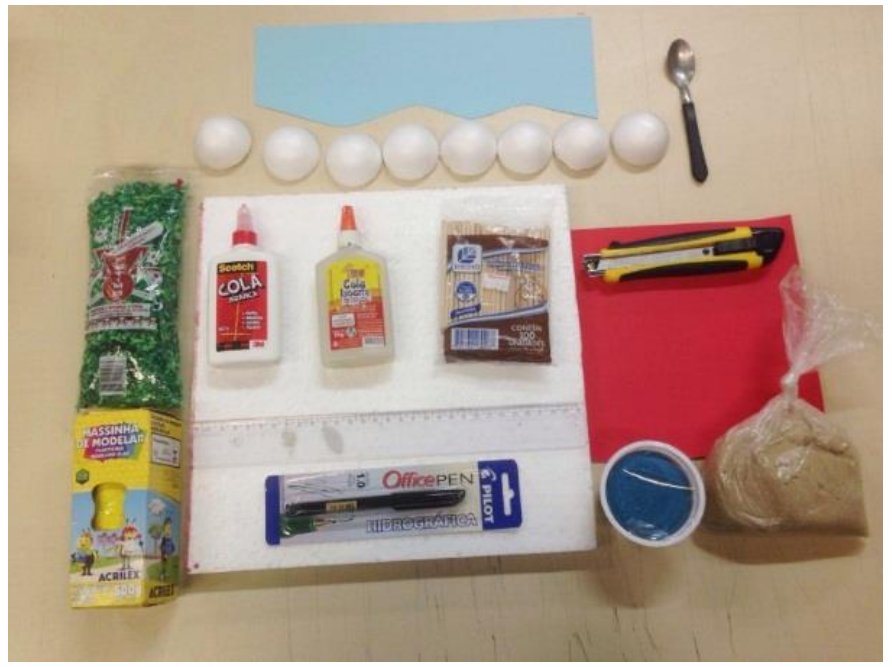

Figura 1 - Materiais utilizados para confeccionar maquete sobre geodiversidade de dunas costeiras

\section{Resultados e Discussões}

Utilizou-se a placa de isopor mencionada como base da maquete. A cartolina azul recortada no tamanho mencionado foi colada em uma das extremidades para a representação do mar. As bolinhas de isopor partidas ao meio e coladas na placa serviram como base para a modelagem das dunas frontais. A massa de modelar amarela foi aplicada em cima destas bolas para criar as dunas frontais. Também foi utilizada para criar as dunas barcanoides. A massa de modelar azul serviu para representar uma lagoa. A grama de 


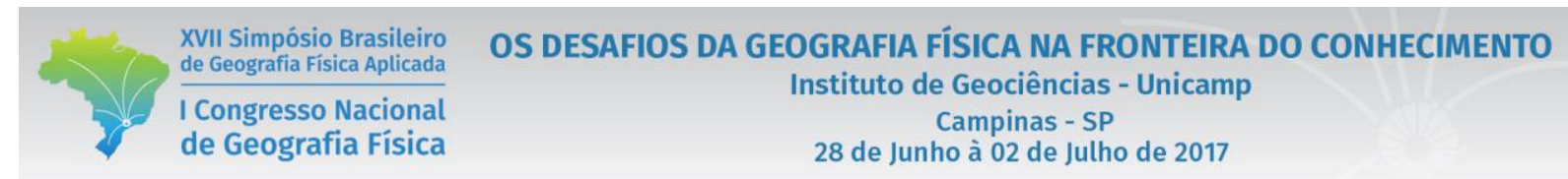

crepom foi colada para retratar a vegetação que atua na fixação das dunas frontais. A areia colada na placa representou a praia. O papel cartão e os palitos foram utilizados para fazer uma placa com a direção predominante do vento.

Definiu-se tanto a escala vertical quanto a horizontal. Verticalmente, $2,5 \mathrm{~cm}$ representam $4 \mathrm{~m}$. Horizontalmente, $5 \mathrm{~cm}$ na maquete representam $20 \mathrm{~m}$ na realidade. Além disso, outro elemento cartográfico se fez presente: o norte geográfico. Desta forma, obteve-se a maquete (figura 2).

O passo a passo para a criação desta maquete foi incluído em uma apostila elaborada pelos membros do projeto GeoPECS para o "Programa de Formação Continuada em parceria com Coordenação Humanas/Arte e Cultura" da Secretaria de Educação do município de Armação de Búzios (RJ). Pôde-se disseminar a construção de maquete representativa de dunas costeiras. Consta, também, na apostila os roteiros dos trabalhos de campo mencionados, informações sobre geodiversidade, geodiversidade costeira e sobre o Parque Estadual da Costa do Sol. Com isto, os professores participantes desse programa podem realizar estas atividades e divulgar a geodiversidade e a importância de sua conservação.

Para Rosa e Nascimento (2016), o emprego de materiais alternativos ao livro didático e que complementam a aula expositiva despertam um maior interesse e compreensão dos alunos. Assim, o uso da maquete para representar e trabalhar a geodiversidade de dunas com alunos do ensino fundamental permite que o tema seja abordado de forma mais agradável e eficiente. Além disso, esse recurso didático também possibilita o ensino de cartografia.

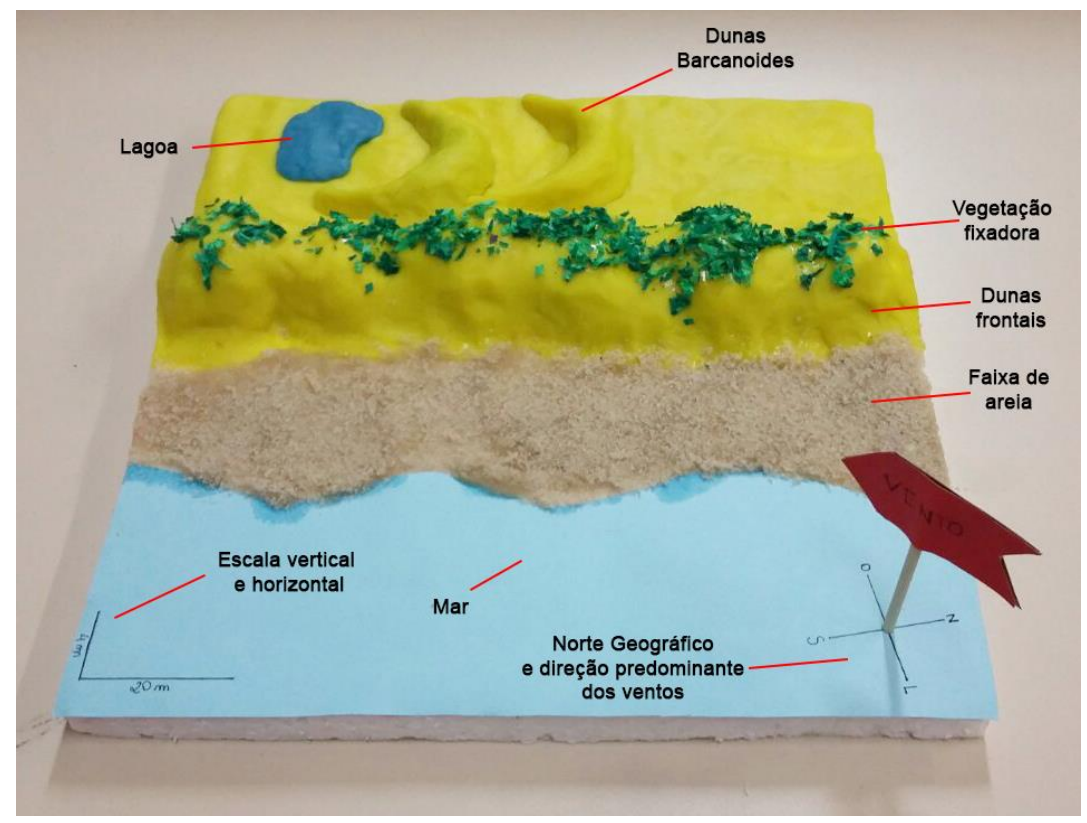

Figura 2 - Maquete de geodiversidade costeira e seus elementos 


\section{Considerações finais}

A geodiversidade tem grande importância para a sociedade, que por sua vez, não a reconhece. Brilha (2005) reporta que um exemplo dessa importância é a capacidade de proporcionar vida na Terra (a biodiversidade é condicionada a geodiversidade). Já Gray (2004) aponta que a falta de conhecimento sobre estes elementos é a maior ameaça que a geodiversidade pode sofrer porque leva a impactos como a depredação desses elementos, seja através de sua extração ilegal ou da destruição do ambiente em que eles se encontram para a realização de obras. Não é diferente com a geodiversidade de dunas costeiras. Desta forma, disseminar este conhecimento é importante para a manutenção desses elementos no planeta. A utilização de materiais didáticos como a maquete na divulgação desse tema com alunos do ensino fundamental torna o ensino mais estimulante e concreto.

\section{REFERÊNCIAS}

ARAÚJO, J.L.L; LOPES, L.S.O. Princípios e Estratégias de Geoconservação. OBSERVATORIUM: Revista Eletrônica de Geografia, v.3, n.7, p. 66-78, out. 2011.

BENTO, L.C.M.; ARAÚJO, M.S. Geoturismo e geoconservação: uma prática de campo. I Simpósio Mineiro de Geografia - Alfenas 26 a 30 de maio de 2014.

BRANDÃO, R.L. 2008. Regiões costeiras in CPRM, Geodiversidade do Brasil: conhecer o passado, para entender o presente e prever o futuro, 264p.

BRILHA, J. 2005. Patrimônio geológico e geoconservação - a conservação da natureza na sua vertente geológica, Palimage Editores, Viseu.

CPRM. 2006. Mapa geodiversidade do Brasil. Escala 1:2.500.000. Legenda expandida. Brasília: CPRM/Serviço Geológico do Brasil, 68 p. CD-ROM.

DA ROSA, E.P; NASCIMENTO, GM. Uso da maquete para o ensino das formas de relevo do Rio Grande do Sul. In: XI SIANGEO, 2016, Maringá - PR. XI SINAGEO, 2016.

DAVIDSON-ARNOTT, R. 2010. An Introduction to Coastal Processes and Geomorphology. Cambridge University Press.

FERNANDEZ, G.B; PEREIRA, T.G; ROCHA, T.B. 2009. Coastal Dunes along Rio de Janeiro Coast: Evolution and Management. Journal of Coastal Researh, SI 56, PP 307-311. 
GRAY, M. 2004. Geodiversity: valuing and conserving abiotic nature. Londres: John Wiley \& Sons Ltd.

HESP, P.A. e WALKER, I.J. Coastal Dunes. 2013. In: John F. Shroder (ed.) Treatise on Geomorphology, Volume 11, pp. 328-355. San Diego: Academic Press.

ROCHA, T.B; SILVA, J.C; COSTA, M.A; MACHADO, B.A. O trabalho de campo como ferramenta de divulgação da geodiversidade das dunas costeiras: um estudo de caso com alunos do ensino fundamental (Armação de Búzios, RJ). In: XI SIANGEO, 2016, Maringá - PR. XI SINAGEO, 2016.

THOMAS, M. 2012. Geodiversity and Landscape Sensitivity: A Geomorphological Perspective. Scottish Geographical Journal Vol. 128, Nos. 3-4, 195-210. 